\title{
Proporções de amônio e nitrato no crescimento de plantas de Lippia alba (Mill) N. E. Br. cultivadas sob ambientes de luz
}

\section{The proportions of ammonium and nitrate on the growth of plants of (Lippia alba (Mill) N. E. Br.). grown under light environments}

\author{
Janderson do C.Lima1,*, ${ }^{1, *}$ Uasley C. de Oliveira², Anacleto R. dos Santos², Aline dos A. Souza² \\ e Girlene S. Souza² \\ * Parte da dissertação de mestrado do primeiro autor. \\ ${ }_{1}^{1}$ Universidade Estadual de Feira de Santana. Feira de Santana-Ba, Avenida Transnordestina, s/n - Novo Horizonte. CEP 44036-900 - Feira de Santana - Ba/Brasil \\ 2 Universidade Federal do Recôncavo da Bahia. Cruz das Almas-BA. Rua Rui Barbosa, 710 - Campus Universitário CEP 44380-000, Cruz das Almas/BA, Brasil \\ ( ${ }^{*}$ E-mail: Janderson_ufrb@yahoo.com.br) \\ http://dx.doi.org/10.19084/RCA17240
}

Recebido/received: 2017.09.19

Aceite/accepted: 2018.04.18

\section{R E S U M O}

O objetivo deste trabalho foi avaliar o crescimento de Lippia alba cultivada em proporções de amônio $\left(\mathrm{NH}_{4}^{+}\right)$e nitrato $\left(\mathrm{NO}_{3}{ }^{-}\right)$e ambientes de luz. As plantas foram submetidas a cinco proporções de $\mathrm{NH}_{4}^{+}: \mathrm{NO}_{3}{ }^{-}$através de soluções nutritivas, e quatro ambientes de luz. As mudas de L. alba foram transplantadas para vasos de plásticos contendo $6 \mathrm{dm}^{3} \mathrm{do}$ substrato, composto por uma mistura de areia lavada + vermiculita na proporção 2:1. Aos 120 dias após a aplicação dos tratamentos foram avaliados os parâmetros: índice de clorofila 'a', 'b', total, relação a/b, fitomassa seca de folhas, caule, raízes, da planta, da parte aérea, volume de raízes, área foliar, razão de área foliar, área foliar específica e razão de massa foliar. As malhas influenciaram significativamente os índices de clorofila. Houve interação significativa entre as proporções de amônio e nitrato com os ambientes de luz para o volume de raízes. As plantas crescidas em solução nutritiva com $100 \%$ do $\mathrm{N}_{-} \mathrm{NO}_{3}$ - assim como sob malha aluminet apresentaram valores de área foliar superiores demais.

Palavras-chave: Malhas coloridas; planta medicinal e nitrogênio.

\begin{abstract}
A B S T R A C T
The objective of this work was to evaluate the growth of Lippia alba under different proportions of ammonium $\left(\mathrm{NH}_{4}^{+}\right)$ and nitrate $\left(\mathrm{NO}_{3}^{-}\right)$and light environments. The plants were subjected to five ratios of $\mathrm{NH}_{4}^{+}: \mathrm{NO}_{3}-$ in nutritive solutions,

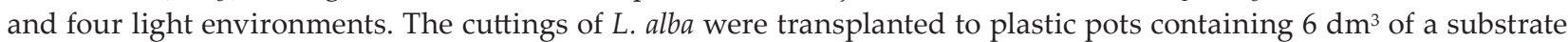
containing a mixture of washed sand + vermiculite in a 2:1 ratio. At 120 days after application of the treatments, the following parameters were evaluated: the index of chlorophyll ' $a$ ', ' $b$ ', total, ratio a/b, dry weight of leaves, stem, roots, plant, aerial part, volume of roots, leaf area, ratio of leaf area, leaf area and specific mass ratio of leaf. The meshes have significantly influenced the indices of chlorophyll. There was significant interaction between proportions of ammonium and nitrate with the environments of light for the volume of roots. The plants grown in nutritive solution with $100 \%$ of $\mathrm{N}^{-\mathrm{NO}_{3}}{ }^{-}$as well as under the mesh aluminet had values of leaf area higher than the others.
\end{abstract}

Keywords: Meshes colored, nitrogen, lemon balm. 


\section{INTRODUÇÃO}

Lippia alba (Mill) N. E. Brown, também conhecida em diversas regiões do Brasil por erva cidreira, erva cidreira brasileira, erva cidreira do campo, alecrim, alecrim do mato, alecrim do campo, etc., apresenta algumas características qualitativas predominantes, como o caule marrom e as folhas de coloração verde-escuro, a nervura da folha e a coloração das sépalas verde, e as pétalas de coloração lilás claro. Essa espécie tem apresentado grande importância na indústria farmacológica e de perfumaria, isto devido suas propriedades fitoterápicas e pelos componentes apresentados em seus óleos essenciais (Tavares et al., 2011; Luz et al., 2014).

O crescimento vegetal não depende apenas do potencial genético da espécie, mas também de diversos fatores que atuam em conjunto, sejam eles: umidade, relevo, luminosidade, irrigação, fatores climáticos, fertilidade do solo entre outros, podendo comprometer o desempenho da planta severamente (Calixto, 2000; Meira et al., 2012; Silva et al., 2015).

Além de cultivos em ambientes naturais, malhas fotoconversoras surgem no mercado com o intuito de combinar a proteção física com a qualidade de luz espectral, essas malhas são produzidas com aditivos especiais que convertem singulares filtros de luz, com isso a luminosidade que chega ao ambiente de cultivo é diferenciada, pois ocorre a conversão da luminosidade direta em difusa estimulando a fotossintese. A malha vermelha possui uma maior transmitância em comprimentos de onda acima de $590 \mathrm{~nm}$ (vermelho) e um pico menor em torno de $400 \mathrm{~nm}$ (violeta), reduzindo ondas azuis, verdes e amarelas. A malha Aluminet atua no controle térmico, não permitindo grandes variações de temperatura dentro do ambiente de cultivo (Polysack, 2012).

Estudos recentes demonstram que o cultivo sob $50 \%$ de sombreamento com o uso de malhas fotoconversoras pode proporcionar várias modificações relacionadas à produção de fitomassa e formação de estruturas produtoras de metabólitos secundários (Martins et al., 2009; Oliveira et al., 2009; Lima et al., 2013; Souza et al., 2014). Além da luminosidade o estado nutricional é importante no desenvolvimento vegetal, pois quando em defict ou toxidez iônica, verifica-se redução no acúmulo de fitomassa. Nessas condições, o equilíbrio nutricional interno da planta através da adubação é essencial para as espécies medicinais.

Dentre os elementos quimicos essenciais o nitrogênio $(\mathrm{N})$ apresenta-se como o nutriente requerido em maior quantidade pelas plantas, pois atua diretamente influenciando o crescimento vegetal, e está relacionado ao metabolismo, se fazendo presente na composição das mais importantes biomoléculas, tais como ATP, NADH, NADPH, clorofila, proteínas, coenzimas e enzimas, além de participar da síntese de vitaminas e hormônios (Bredemeier \& Mundstock, 2000). É considerado como o nutriente mais crítico para a produtividade agrícola (Borges et al., 2007). Apesar das diferentes formas que este pode ser absorvido, há uma preferência pelo $\mathrm{N}$-amoniacal e Nítrico, sendo essas as formas mais abundantes na solução do solo e pela qual o $\mathrm{N}$ pode ser absorvido e metabolizado pelos vegetais (Taiz \& Zeiger, 2010).

Trabalhos científicos realizados com o amendoinzeiro e o girassol (Ribeiro et al., 2012; Alves et al., 2013), apresentaram dados que evidenciou-se efeito negativo sobre o crescimento vegetal, quando o nitrogênio só era fornecido na forma amoniacal, isso se atribui à necessidade de utilização dos carboidratos produzidos o que não é desejável para as culturas (Britto \& Kronzucker, 2002).

Diante do exposto o objetivo deste trabalho foi avaliar a crescimento de $L$. alba cultivada sob ambientes de luz e diferentes proporções de amônio e nitrato.

\section{MATERIAL E MÉTODOS}

\section{Produção das mudas}

Mudas de L. alba foram produzidas a partir de estacas, em viveiro pertencente ao Centro de Ciências Agrárias, Ambientais e Biológicas da Universidade Federal do Recôncavo da Bahia UFRB. Os ramos utilizados para a estaquia foram produzidos a partir de uma planta matriz, espécie que foi identificada e a exsicata encontra-se depositada no Herbário da referida Universidade, situado 
em Cruz das Almas-BA, com número de tombamento da planta de HURB 8806.

O material vegetal foi enraizado em substrato contendo areia lavada, em bandejas de polietileno. Após o enraizamento, as plantas foram selecionas tendo em media $10 \mathrm{~cm}$ de altura e $12 \mathrm{~cm}$ de comprimento radicular, e assim foram transplantadas para vasos de plásticos contendo $6 \mathrm{dm}^{3}$ de areia lavada + vermiculita na proporção 2:1.

\section{Implantação e delineamento experimental}

O experimento foi desenvolvido no campo experimental do Centro de Ciências Agrárias, Ambientais e Biológicas da Universidade Federal do Recôncavo da Bahia - UFRB, no Município de Cruz das AlmasBahia (1240" S; 390" ${ }^{\circ}$ ' W; 226 metros de altitude), no período de dezembro de 2015 a abril de 2016.

O delineamento experimental utilizado foi inteiramente casualizado em esquema fatorial $5 \times 4$, sendo cinco proporções de amônio e nitrato (100:0; 75:25; 50:50; 25:75 e 0:100) (Quadro 1) e quatro ambientes de luz, obtidos com o uso das malhas coloridas ChromatiNET vermelha, preta e aluminizada

Quadro 1 - Volume ( $\mathrm{mL}$ ) das soluções estoque para formar $1 \mathrm{~L}$ de solução nutritiva modificada, utilizando proporções de amônio e nitrato $\left(\mathrm{NH}_{4}^{+}: \mathrm{NO}_{3}{ }^{-}\right)$ conforme os respectivos tratamentos

\begin{tabular}{|c|c|c|c|c|c|}
\hline \multirow{2}{*}{ Solução estoque } & \multicolumn{5}{|c|}{ Proporções de $\left(\mathrm{NH}_{4}^{+}: \mathrm{NO}_{3}^{-}\right)$} \\
\hline & 100:0 & $75: 25$ & $50: 50$ & $25: 75$ & 0:100 \\
\hline \multirow{2}{*}{\multicolumn{6}{|c|}{ (1M) }} \\
\hline & & & & & \\
\hline $\mathrm{KH}_{2} \mathrm{PO}_{4}$ & 1,0 & 1,0 & 1,0 & 1,0 & 1,0 \\
\hline $\mathrm{NH}_{4} \mathrm{Cl}$ & 15,0 & 11,25 & 7,5 & 3,75 & - \\
\hline $\mathrm{KCl}$ & 5,0 & 1,25 & 5,0 & 3,75 & - \\
\hline $\mathrm{CaCl}_{2}$ & 5,0 & 5,0 & 1,25 & - & - \\
\hline $\mathrm{MgSO}_{4}$ & 2,0 & 2,0 & 2,0 & 2,0 & 2,0 \\
\hline $\mathrm{KNO}_{3}$ & - & 3,75 & - & 1,25 & 5,0 \\
\hline $\mathrm{Ca}\left(\mathrm{NO}_{3}\right)_{2}$ & - & - & 3,75 & 5,0 & 5,0 \\
\hline Micronutrientes** & 1,0 & 1,0 & 1,0 & 1,0 & 1,0 \\
\hline Ferro - EDTA* & 1,0 & 1,0 & 1,0 & 1,0 & 1,0 \\
\hline
\end{tabular}

**Solução de micronutrientes $(\mathrm{g} / \mathrm{l}): \mathrm{H}_{3} \mathrm{BO}_{3}=2,86 ; \mathrm{MnCl}_{2} 4 \mathrm{H}_{2} \mathrm{O}=1,81 ; \mathrm{ZnCl}_{2}$ $=0,10 ; \mathrm{CuCl}_{2}=0,04 ; \mathrm{H}_{2} \mathrm{MoO}_{4} \mathrm{H}_{2} \mathrm{O}=0,02$. *Solução de Ferro-EDTA: Foram dissolvidos 26,1 g de EDTA dissódico em $286 \mathrm{ml}$ de $\mathrm{NaOH} 1 \mathrm{~N}+24,9 \mathrm{~g}$ de $\mathrm{FeSO}_{4} \cdot 7 \mathrm{H}_{2} \mathrm{O}$ e aerado por uma noite.
(Polysack Plastic Industries ${ }^{\circledR}$ ) e o tratamento a pleno sol utilizado como testemunha. Cada tratamento conteve cinco repetições sendo uma planta por vaso, totalizando 100 unidades experimentais.

Os tratamentos foram estabelecidos tendo como base a concentração de nitrogênio (N) utilizada pela solução de Hoagland \& Arnon (1950). A solução nutritiva foi composta por macro e micronutrientes na concentração em $\mathrm{mg} \mathrm{L}^{-1}$ : $\mathrm{N}=$ 210, $\mathrm{P}=31, \mathrm{~K}=234, \mathrm{Ca}=200, \mathrm{Mg}=48$ e $\mathrm{S}=64$, com $\mathrm{pH}=5,6( \pm 1)$. A distribuição dos tratamentos foi iniciada oito dias após o transplante e aclimatação das mudas.

\section{Análise de Crescimento}

Percorridos 120 dias após a implantação do experimento em campo foram avaliados os parâmetros de crescimento. Com a utilização de uma proveta graduada contendo um volume conhecido de água foi determinado o volume da raízes, essas foram imersas e pela diferença na coluna d'água, obteve-se o volume de raízes $\left(\mathrm{cm}^{3}\right)$. O número de folhas em cada tratamento foi obtido através da contagem direta.

Além disso, foram avaliados os índices de clorofila $a, b$, total $(a+b)$ e relação $a / b$, através do medidor eletrônico (ICF - Índice de Clorofila Folker). Esse aparelho possui área foliar de medição de $50,3 \mathrm{~mm}^{2}$, e atua emitindo nas folhas 3 faixas de frequência, permitindo uma análise detalhada. A medição foi feita em folhas intactas de Lippia entre as 08:00 e 10:00h da manhã.

\section{Determinação da fitomassa}

Os componentes folhas, caules e raízes das plantas de $L$. alba foram coletados e acondicionados individualmente em sacos de papel, colocadas em estufa, com circulação forçada de ar, $45^{\circ} \mathrm{C} \pm 2{ }^{\circ} \mathrm{C}$, até atingir peso constante. Foram analisadas as variáveis fitomassa seca da folha (MSF), fitomassa seca do caule (MSC), e fitomassa seca da raiz (MSR), utilizando-se de uma balança analítica com precisão de três casas. A partir deste, foram calculados massa seca de parte aérea (MSPA) e massa seca da planta (MSP). 


\section{Determinação dos índices fisiológicos}

A área foliar (AF) foi determinada com a utilização de um perfurador de área conhecida (de metal), através de punções, tomam-se amostras de discos foliares, relacionando a massa seca da área conhecida do disco com a massa seca da folha, sendo expressos $\mathrm{em}^{\mathrm{cm}^{2}}$. A partir dos valores de área foliar (AF) expressos em $\mathrm{cm}^{2}$, fitomassa seca de folhas (MSF) e fitomassa seca total (MSP), ambos expressos em $\mathrm{g}$, foi realizadas as análise de crescimento a partir de fórmulas matemáticas descritas por Peixoto (2011) onde foi determinados à razão de área foliar (RAF) que é determinada através da AF/MSP, parâmetro esse que tende a declinação enquanto a planta cresce, devido ao autosombreamento.

A área foliar específica (AFE) parâmetro calculado através da AF/ MSF, variável de grande relevância, pois a superfície é o componente morfológico e a fitomassa é o componente anatômico, está relação entre a composição interna formada e pelo número e/ou tamanho de células do mesófilo foliar representa a área foliar. Para determinar a razão de massa foliar (RMF) calculada por MSF/MSP, representa a massa seca retida nas folhas, é a fração que não foi exportada. Sendo todos esses expressos em $\mathrm{cm}^{2} \mathrm{~g}^{-1}$.

\section{Análise estatística}

Os resultado foram submetidos à análise estatística de variância, e em função do nível de significância pelo teste de $\mathrm{F}$, para proporções $\mathrm{NH}_{4}{ }^{+}: \mathrm{NO}_{3}{ }^{-}$, ambientes de luz e a interação destes, procederam-se o teste de médias (Tukey 5\%), utilizando-se o programa estatístico SISVAR® 5.3 (Ferreira, 2008).

\section{RESULTADOS E DISCUSSÃO}

Os resultados encontrados para os índices de clorofila a, b e total (Quadro 2), revelaram o efeito significativo das plantas crescidas sob as malhas vermelha, aluminet e preta, em relação àquelas cultivadas a pleno sol. Plantas crescidas sob as malhas coloridas não diferiram entre si.
O índice de clorofila "a" foi cerca de 7\% maior nas plantas crescidas sob a malha vermelha e aluminet em comparação aquelas ao pleno sol. Esse tipo de clorofila está presente em organismos que realizam fotossíntese oxigênica, é o pigmento utilizado para realizar a fotoquímica, enquanto os demais pigmentos auxiliam na absorção da luminosidade e na transferência dessa energia para os centros de reação, dentre esses pigmentos também chamados de acessórios temos a clorofila $b$. Analisando os valores do índice de clorofila " $b$ ", verificou-se aumento de $27 \%$ e $25 \%$ das plantas sob malha vermelha e aluminet respectivamente, em relação ao ambiente não sombreado, provavelmente o sombreamento induziu as plantas à síntese de clorofilas. A relação $\mathrm{Cla} / \mathrm{Clb}$ demonstrou efeito contrario, ou seja, as plantas cultivadas à pleno sol apresentaram valores significativamente superior as demais, isto está atrelado ao baixo valor encontrado entre os índices de $\mathrm{Cla}$ e $\mathrm{Clb}$ nesse ambiente de luz.

A fitomassa seca das folhas, caules, raízes e parte aérea da $L$. alba quando submetidas as proporções de amônio e nitrato (Quadro 3), verificou-se efeito significativo em todas variáveis, quando foi fornecido o nitrogênio nas soluções nutritivas com 50\% ou mais de nitrato, ou seja quando as plantas que continham em maior proporções íons de amônio o acumulo de massa seca foi reduzido. Quanto aos valores de MSP, constatou-se uma redução de 30\% entre o tratamento com $100 \%$ de amônio como fonte de nitrogênio em comparação aquele que continha o nitrato como única fonte na solução.

Quadro 2 - Índice de clorofila a, Índice de clorofila b, Índice de clorofila total e Relação Cla/Clb (Cla: Clorofila a e Clb: clorofila b), para plantas de Lippia alba cultivadas sob proporções de amônio e nitrato e ambientes de luz. Cruz das Almas-BA, 2017

\begin{tabular}{ccccc}
\hline Tratamentos & $\begin{array}{c}\text { Índice de } \\
\text { clorofila }\end{array}$ & $\begin{array}{c}\text { Índice de } \\
\text { clorofila }\end{array}$ & $\begin{array}{c}\text { Índice de } \\
\text { clorofila }\end{array}$ & $\begin{array}{c}\text { Relação } \\
\text { Cla/Clb }\end{array}$ \\
\hline Ambientes de Luz & & $\mathbf{b}$ & total & \\
\hline Pleno Sol & $27,03 \mathrm{~b}$ & $9,01 \mathrm{~b}$ & $36,05 \mathrm{~b}$ & $3,13 \mathrm{a}$ \\
Malha vermelha & $29,07 \mathrm{a}$ & $11,42 \mathrm{a}$ & $40,49 \mathrm{a}$ & $2,58 \mathrm{~b}$ \\
Malha Aluminet & $28,99 \mathrm{a}$ & $11,27 \mathrm{a}$ & $40,26 \mathrm{a}$ & $2,61 \mathrm{~b}$ \\
Malha preta & $28,22 \mathrm{ab}$ & $10,55 \mathrm{a}$ & $38,78 \mathrm{a}$ & $2,72 \mathrm{~b}$ \\
\hline
\end{tabular}

*Letras iguais não diferem entre si nas colunas, pelo teste de Tukey a $5 \%$ de probabilidade. 
$\mathrm{O} \mathrm{N}$ na forma amoniacal em maiores percentuais, possivelmente afetou a translocação dos fotoassimilados da parte aérea para as raízes, isso porque o processo de assimilação do íon amônio requer a presença de esqueletos de carbono e energia, a fim de evitar seu acúmulo em níveis tóxicos (Lewis et al., 1989).

Os parâmetros referentes ao rendimento de fitomassa seca de folhas das plantas de L. alba crescidas sob malhas vermelha e aluminet foram superiores em $90 \%$ e $104 \%$ respectivamente em relação aquelas cultivadas a pleno sol. Considerando que as folhas são o principal material comercializado pelas plantas medicinais, esses resultados indicam que o uso dessas malhas coloridas podem ser indicadas para esses fins.

Fazendo a mesma comparação para a MSC, verificou-se um ganho nas plantas crescidas sob malhas vermelha de $69 \%$ e na aluminet $80 \%$. Em relação a MSR, constatou-se que nos resultados observados não houve diferenças entre as malhas coloridas, porém, esses valores foram superiores aqueles das plantas cultivadas a pleno sol. Esses resultados demonstram que houve efeito exclusivo do sombreamento das malhas e não da qualidade de luz, o que influencia diretamente no volume de

Quadro 3 - Fitomassa seca de folhas (MSF), do caule (MSC), de raiz (MSR), da planta (MSP) e da parte aérea (MSPA), de plantas de Lippia alba cultivadas sob proporções de amônio e nitrato e ambientes de luz. Cruz das Almas-BA, 2017

\begin{tabular}{|c|c|c|c|c|c|}
\hline \multirow[b]{2}{*}{ Tratamentos } & MSF & MSC & MSR & MSP & MSPA \\
\hline & \multicolumn{5}{|c|}{ - } \\
\hline \multicolumn{6}{|l|}{$\mathrm{NH}_{4}^{+}: \mathrm{NO}_{3}^{-}$} \\
\hline 100:0 & $2,41 b$ & $12,84 \mathrm{c}$ & $3,22 b$ & $18,48 \mathrm{c}$ & $15,25 \mathrm{~b}$ \\
\hline & $30 \mathrm{~b}$ & $15,06 \mathrm{~b}$ & $4,16 \mathrm{~b}$ & $21,53 \mathrm{~b}$ & $17,36 \mathrm{~b}$ \\
\hline $50: 50$ & $2,64 a b$ & $18,13 \mathrm{a}$ & $5,42 \mathrm{a}$ & $26,21 \mathrm{a}$ & $20,78 \mathrm{a}$ \\
\hline $25: 75$ & $2,55 \mathrm{ab}$ & $18,22 \mathrm{a}$ & $5,52 \mathrm{a}$ & $26,29 \mathrm{a}$ & 20,77 a \\
\hline $0: 100$ & $2,91 \mathrm{a}$ & $18,32 \mathrm{a}$ & 5,47 a & $26,71 \mathrm{a}$ & $21,24 \mathrm{a}$ \\
\hline \multicolumn{6}{|l|}{ Ambientes de Luz } \\
\hline Pleno Sol & $\mathcal{D}$ & $11,05 \mathrm{c}$ & $3,77 \mathrm{~b}$ & $16,53 \mathrm{c}$ & $12,76 \mathrm{c}$ \\
\hline Malha vern & $3,23 \mathrm{a}$ & $18,64 \mathrm{a}$ & $4,88 \mathrm{a}$ & $26,75 \mathrm{a}$ & $21,87 \mathrm{a}$ \\
\hline Malha Aluminet & $3,48 \mathrm{a}$ & $19,88 \mathrm{a}$ & 4,83 a & $28,20 \mathrm{a}$ & $23,36 \mathrm{a}$ \\
\hline Malha preta & $1,80 \mathrm{~b}$ & $16,21 \mathrm{~b}$ & $5,49 \mathrm{a}$ & $23,51 \mathrm{~b}$ & $18,02 \mathrm{~b}$ \\
\hline
\end{tabular}

*Letras iguais não diferem entre si nas colunas, pelo teste de Tukey a $5 \%$ de probabilidade. raízes dessas planta. Esse incremento nas raízes das plantas, provavelmente esta relacionado à biossíntese de citocininas, o que promoveu uma maior citocinese, ou seja elevação da divisão celular.

Para a MSPA os valores apresentados entre as plantas cultivadas sob as malhas vermelha e aluminet em relação ao pleno sol, foram superiores em 71 e $83 \%$ respectivamente. Fazendo uma comparação para a variável MSP, destaca-se que as plantas de Lippia quando cultivadas sob a malha aluminet apresentaram um incremento de $70 \%$ em relação as plantas cultivadas a pleno sol, evidenciando a importância da utilização desse ambiente de cultivo para o parâmetro estudado.

$\mathrm{Na}$ interação (Quadro 4) entre as proporções de amônio e nitrato estudadas e os ambientes de luz, verificou-se que as proporções 100:0 e 75:25 de amônio e nitrato, interagiram significativamente com o volume de raízes nas plantas sob as malhas vermelha e aluminet. $\mathrm{O}$ mesmo se observa nas plantas submetidas às interações contendo 50:50 de $\mathrm{NH}_{4}^{+}: \mathrm{NO}_{3}$ - e crescidas sob malha preta, assim como as proporções 25:75 e 0:100 com todos os ambientes de luz, com exceção da malha vermelha com a última proporção.

A variável volume de raízes, tem importância destacada em relação ao manejo da cultura, pois quanto maior for volume da raiz, em condições normais, maior será a absorção de água e sais minerais pelas plantas, o que vai ser importantíssimo no seu crescimento e desenvolvimento. O maior volume de raízes das plantas observado foi identificado na interação entre a proporção de amônio e nitrato $50 \%$ e a malha preta, sendo cerca de $194 \%$ superior ao menor volume encontrado, que foi nas plantas a pleno sol na proporção com $100 \%$ de amônio.

Houve efeito significativo para as proporções amônio e nitrato e para os ambientes de luz, conforme demonstrado no Quadro 5. A AF foi influenciada pelas soluções nutritivas que continham 25:75 e 0:100 de amônio e nitrato. Assim como nas variáveis de fitomassa, quando o $\mathrm{NH}_{4}^{+}$ apresentava-se em grandes concentrações na solução houve uma significativa redução nos valores obtidos. 
Quadro 4 - Desdobramento da interação entre as proporções de amônio e nitrato e os ambientes de luz para a variável volume de raiz em plantas de Lippia alba cultivadas sob proporções de amônio e nitrato e ambientes de luz. Cruz das Almas-BA, 2017

\begin{tabular}{ccccc}
\hline \multicolumn{5}{c}{ Volume de Raiz } \\
\hline \multirow{5}{*}{$\mathbf{N H}_{4}{ }^{+} \mathbf{N O}_{3} \mathbf{3}^{-}$} & \multicolumn{4}{c}{ Ambientes de Luz } \\
\cline { 2 - 5 } & Pleno Sol & $\begin{array}{c}\text { Malha } \\
\text { Vermelha }\end{array}$ & $\begin{array}{c}\text { Malha } \\
\text { Aluminet }\end{array}$ & $\begin{array}{c}\text { Malha } \\
\text { preta }\end{array}$ \\
\hline $100: 0$ & $7,60 \mathrm{cA}$ & $10,40 \mathrm{aA}$ & $9,00 \mathrm{aA}$ & $9,80 \mathrm{cA}$ \\
$75: 25$ & $12,00 \mathrm{bcA}$ & $11,60 \mathrm{aA}$ & $9,20 \mathrm{aA}$ & $12,80 \mathrm{bcA}$ \\
$50: 50$ & $11,50 \mathrm{bcB}$ & $13,20 \mathrm{aB}$ & $13,20 \mathrm{aB}$ & $22,40 \mathrm{aA}$ \\
$25: 75$ & $15,20 \mathrm{abA}$ & $14,20 \mathrm{aA}$ & $12,80 \mathrm{aA}$ & $17,60 \mathrm{abA}$ \\
$0: 100$ & $18,20 \mathrm{aA}$ & $11,40 \mathrm{aB}$ & $11,20 \mathrm{aB}$ & $17,80 \mathrm{abA}$ \\
\hline
\end{tabular}

*letra minúscula para comparação entre colunas e maiúscula em linhas, pelo teste de Tukey a $5 \%$ de probabilidade.

Em relação aos ambientes de luz, só foi observada incremento significativo de AF nas plantas cultivadas sob malha aluminet. Esse parâmetro é de suma importância visto que plantas com significativos valores de AF podem aumentar a sua eficiência fotossintética devido a maior área de absorção da luminosidade. A RAF apresentou significância nas soluções quando continha apenas uma forma de N, ou seja, amônio ou nitrato. Esse parametro de crescimento apresenta declinio enquanto a planta cresce, em função do autosombreamento, tendendo a redução da AF fotossinteticamente ativa.

Todas as proporções influenciaram na AFE com exceção das plantas que com solução de 50\% amônio e nitrato. Para a RMF que representa a massa da matéria seca acumulada na planta, as proporções não diferiram entre si com exceção da solução com $100 \%$ de amônio, que se mostrou superior as demais. Nesses três últimos parâmetros foi observado que as plantas crescidas sob as malhas vermelha e aluminet foram significativamente superior aos demais ambientes e que não diferiram entre si.

Em efeito comparativo, os resultados apresentados para $\mathrm{AF}$, percebe-se que as plantas crescidas sob solução nutritiva contendo a forma nítrica como única fonte de $\mathrm{N}$, os valores foram $27 \%$ superior em relação aos encontrados nas soluções que continham somente amônio como forma de N. Estudo utilizando essas mesmas proporções de $\mathrm{N}$ em
Quadro 5 - Área foliar (AF), razão de área foliar (RAF), área foliar especifica (AFE) e razão de massa foliar (RMF) de plantas de Lippia alba cultivadas sob proporções de amônio e nitrato e ambientes de luz. Cruz das Almas-BA, 2017

\begin{tabular}{cclll}
\hline \multirow{2}{*}{ Tratamentos } & \multirow{2}{*}{$\begin{array}{c}\text { Área Foliar } \\
\left(\mathbf{c m}^{2}\right)\end{array}$} & \multicolumn{1}{c}{ RAF } & \multicolumn{1}{c}{ AFE } & RMF \\
\cline { 3 - 5 } & & & & \\
\hline $\mathbf{N H}_{4}{ }^{+}: \mathbf{N O}_{3}{ }^{-}$ & & & & \\
\hline $100: 0$ & $550,72 \mathrm{~b}$ & $29,00 \mathrm{a}$ & $220,60 \mathrm{ab}$ & $0,13 \mathrm{a}$ \\
$75: 25$ & $530,47 \mathrm{~b}$ & $23,93 \mathrm{bc}$ & $222,57 \mathrm{ab}$ & $0,10 \mathrm{~b}$ \\
$50: 50$ & $580,78 \mathrm{~b}$ & $21,33 \mathrm{c}$ & $215,94 \mathrm{~b}$ & $0,09 \mathrm{~b}$ \\
$25: 75$ & $622,36 \mathrm{ab}$ & $23,23 \mathrm{bc}$ & $239,25 \mathrm{a}$ & $0,09 \mathrm{~b}$ \\
$0: 100$ & $702,28 \mathrm{a}$ & $25,71 \mathrm{ab}$ & $232,93 \mathrm{ab}$ & $0,10 \mathrm{~b}$ \\
\hline Ambientes de Luz & & & & \\
\hline Pleno Sol & $322,49 \mathrm{c}$ & $20,24 \mathrm{~b}$ & $189,54 \mathrm{c}$ & $0,10 \mathrm{~b}$ \\
Malha vermelha & $783,26 \mathrm{~b}$ & $29,55 \mathrm{a}$ & $244,23 \mathrm{a}$ & $0,12 \mathrm{ab}$ \\
Malha Aluminet & $880,77 \mathrm{a}$ & $31,55 \mathrm{a}$ & $253,05 \mathrm{a}$ & $0,13 \mathrm{a}$ \\
Malha preta & $392,43 \mathrm{c}$ & $17,18 \mathrm{~b}$ & $217,18 \mathrm{~b}$ & $0,07 \mathrm{c}$ \\
\hline
\end{tabular}

*Letras iguais não diferem entre si pelo teste de Tukey a 5\% de probabilidade.

girassol, Alves et al. (2013), verificaram desempenho similar, sendo cerca de $64,27 \%$ o valor obtido quando era fornecido o $\mathrm{N}^{-\mathrm{NO}_{3}}$. Ainda nesse parâmetro foi verificado que plantas de $L$. alba crescidas sob a malha aluminet apresentaram valores $61 \%$ superiores aos encontrados no cultivo a pleno sol. Esses dados corroboram com os encontrados por Souza et al. (2013), que avaliando a área foliar de Mentha piperita sob ambientes de luz, verificou que as plantas crescidas sob malhas coloridas apresentavam valores muito superiores aos do cultivo a pleno sol, isso porque as plantas quando submetidas a ambientes sombreados tendem a expandir a $\mathrm{AF}$ e consequentemente aumentar a área de receptividade luminosa.

De acordo com Taiz \& Zeiger (2010), as plantas quando submetidas a níveis reduzidos de irradiância, como estratégia adaptativa elas expandem suas folhas para poder aumentar a captação da energia luminosa e com isso promover uma maior eficiência fotossintética, que consequentemente, maior fixação de carbono.

\section{CONCLUSÕES}

As malhas preta, vermelha e aluminet influenciam significativamente os índices de clorofila. 
As plantas de $L$. alba crescidas sob $100 \%$ de $\mathrm{N}^{-\mathrm{NH}_{4}{ }^{+}}$ e sob os ambientes de luz a pleno sol e malha preta, apresenta limitações no rendimento de massa seca.

O volume de raízes das plantas de L. alba é influenciado pela interação ambientes de luz e as proporções de amônio e nitrato.
Plantas de L. alba crescidas com solução contendo $100 \%$ de $\mathrm{N}^{-\mathrm{NO}_{3}}$ - apresentam maior área foliar em relação as demais. Assim como para aquelas cultivadas sob malha aluminet.

\section{REFERÊNCIAS BIBLIOGRÁFICAS}

Alves, A.C.; Jesus, F.N.; Silva, P.C.C.; Santos, A.R. \& Souza, G.S. (2013) - Diagnose nutricional de mudas de girassol submetidas a proporções de amônio e nitrato. Enciclopédia Biosfera, vol. 9, n. 16, p. 723.

Bredemeier, C. \& Mundstock, C.M. (2000) - Regulação da absorção e assimilação do nitrogênio nas plantas. Ciência Rural, vol. 30, n. 2, p. 365-372. http://dx.doi.org/10.1590/S0103-84782000000200029

Britto, D.T. \& Kronzucker, H.J. (2002) $-\mathrm{NH}_{4}{ }^{+}$toxicity in higher plants: a critical review. Journal of Plant Physiology, vol. 159, n. 6, p. 567-584. https://doi.org/10.1078/0176-1617-0774

Calixto, J.B. (2000) - Efficacy, safety, quality control, market and regulatory guidelines for herbal medicines (phytotherapeutic agents). Brazilian Journal of Medical and Biological Research, vol. 33, n. 2, p. 179-189. http:// dx.doi.org/10.1590/S0100-879X2000000200004

Ferreira, D.F. (2008) - Sisvar: um programa para análises e ensino de estatística. Revista Symposium, vol. 6, p. 36-41.

Hoagland, D.R. \& Arnon, D.I. (1950) - The water-culture method for growing plants without soil. California Agricultural Experimental Station. Circ. p. 347.

Lewis, O.A.M.; Leidi, E.O. \& Lips, S.H. (1989) - Effect of nitrogen source on growth response to salinity stress in maize and wheat. New Phytologist, vol. 111, n. 2, p. 55-160. https://doi.org/10.1111/j.1469-8137.1989.tb00676.x

Lima, J.C.; Oliveira, U.C.; Silva, J.S. \& Souza, G.S. (2013) - Adubação fosfatada e qualidade de luz na produção de biomassa do capim-limão. Enciclopédia biosfera, Centro Científico Conhecer, vol. 9, n. 16.

Luz, J.M.Q.; Santos, V.A.; Rodrigues, T.M.; Arrigoni Blank, M.F. \& Asmar, S.A. (2014) - Estabelecimento in vitro e aclimatização de Lippia alba (Mill.) NE Brown. Revista Brasileira de Plantas Medicinais, vol. 16, n. 2, supl. 1, p. 444-449. http://dx.doi.org/10.1590/1983-084X/12_140

Martins, J.R.; Alvarenga, A.A.; Castro, E.M.; Silva, A.P.O.; Oliveira, C. \& Alves, E. (2009) - Anatomia foliar de alfavaca-cravo cultivadas sob malhas coloridas. Ciência Rural, vol. 39, n. 1, p. 82-87. http://dx.doi.org/10.1590/ S0103-84782008005000040

Meira, M.R.; Martins, E.R. \& Manganoti, S.A. (2012) - Crescimento e produção de fitomassa e teor de óleo essencial de melissa (Melissa officinalis L.) sob diferentes níveis de sombreamento. Revista Brasileira de Plantas Medicinais, vol. 14, n. 2, p. 352-357. http://dx.doi.org/10.1590/S1516-05722012000200015

Oliveira, M.I.; Castro, E.M.; Costa, L.C.B. \& Oliveira, C. (2009) - Características biométricas, anatômicas e fisiológicas de Artemisia vulgaris L. cultivada sob telas coloridas. Revista Brasileira de Plantas Medicinais, vol. 11, n. 1, p. 56-62. http://dx.doi.org/10.1590/S1516-05722009000100010

Peixoto, C.P.; Cruz, T.V. \& Peixoto, M.F.S. (2011) - Análise quantitativa do crescimento de plantas: Conceitos e Prática. Enciclopédia Biosfera, vol. 7, p. 51-76.

Polysack (2016) - Soluções em manejo do espectro. [cit. 2016.11.21]. www.polysack.com.br.

Ribeiro, M.O; Boechat, C.L.; Conceição, M.G.S.; Moreira, F.M.; Ribeiro, L.M. \& Santos, A.R. (2012) - Efeito das interações entre os íons amônio e nitrato na fisiologia do crescimento do amendoinzeiro. Revista Ceres, vol. 59, n. 5, p. 630-635. http://dx.doi.org/10.1590/50034-737X2012000500008

Silva, R.A.L.; Soares, J.D.R.; Dias, G.D.M.G.; Pasqual, M.; Chagas, E.A. \& Gavilanes, M.L. (2015) - Cultivo de tamarindo sob malhas coloridas: plasticidade anatômica foliar. Ciência Rural, vol. 45, n. 2, p. 238-244. http://dx.doi.org/10.1590/0103-8478cr20140012 
Souza, G.S.; Silva, J.S.; Oliveira, U.C. \& Santos, A.R. (2014) - Vegetative growth and yield of essential oil of the Rosemary plants development when cultivated under colored screens. Bioscience Journal, vol. 30, p. 232-239.

Souza, G.S.; Oliveira, U.C.; Silva, J.S. \& Lima, J.C. (2013) - Crescimento, produção de biomassa e aspectos fisiológicos de plantas de Mentha piperita L. cultivadas sob diferentes doses de fósforo e malhas coloridas. Global Science and Technology, vol. 6, n. 3, p.35-44. http://dx.doi.org/10.14688/1984-3801.V06N03A04

Taiz, L. \& Zeiger, E. (2010) - Fisiologia vegetal. $4^{\mathrm{a}}$ ed. Porto Alegre, Artmed. 719 p.

Tavares, I.B.; Momenté, V.G. \& Nascimento, I.R. (2011) - Lippia alba; estudos químicos, etnofarmacológicos e agronômicos. Revista Brasileira de Tecnologia Aplicada nas Ciências Agrárias, vol. 4, n. 1, p. 204-220. 